\title{
ALICERCE PARA ENFRENTAMENTOS DOS DESAFIOS DIÁRIOS NA DOCÊNCIA: FORMAÇÃO INICIAL E CONTINUADA
}

\section{ARTIGO ORIGINAL}

SENA, Alessandra Guilherme Domingos ${ }^{1}$, SANTOS, Raylan Lima dos ${ }^{2}$

SENA, Alessandra Guilherme Domingos. SANTOS, Raylan Lima dos. Alicerce para enfrentamentos dos desafios diários na docência: formação inicial e continuada. Revista Científica Multidisciplinar Núcleo do Conhecimento. Ano. 07, Ed. 01, Vol. 03, pp. 81-102. Janeiro de 2022. ISSN: 2448-0959, Link de acesso: https://www.nucleodoconhecimento.com.br/educacao/enfrentamentos-dosdesafios

\section{RESUMO}

Este trabalho registra uma discussão dos resultados da pesquisa documental que teve como propósito estudar os significados teóricos da formação inicial e continuada docente frente às necessidades da escola pública brasileira. Compreende-se que os docentes passam por vários desafios físicos, estruturais, emocionais, financeiros, entre outros, durante os anos no sistema educacional. Desse modo, descreve-se o quanto uma formação inicial e continuada de qualidade contribuirá para que os docentes tenham embasamento teórico e criticidade para vencer as dificuldades e, assim, direcionar, de forma ética, criativa e positiva, os rumos da educação. Este é um estudo bibliográfico de natureza qualitativa, no qual se ressalta que a questão da

1 Pós-graduada em Gestão Escolar pela FCE; Pós-graduada em Inspeção escolar pela Faculdade São Luís; Graduada em Pedagogia pela Universidade Severino Sombra.

${ }^{2}$ Graduado em Pedagogia Pelo Centro Universitário UNINTER.

RC: 105006

Disponível em: https://www.nucleodoconhecimento.com.br/educacao/enfrentamentos-dosdesafios 
formação se insere em um contexto muito mais amplo na medida em que se articula, através da educação, às lutas em prol da democratização do conhecimento no país.

Palavras-chave: formação inicial, formação continuada, docentes.

\section{INTRODUÇÃO}

Este trabalho foi baseado em pesquisas bibliográficas com foco no ensino público dos anos iniciais do ensino fundamental, com o objetivo de fomentar os assuntos sobre a importância da formação inicial e continuada de qualidade para docentes, levando em consideração a reflexão desse profissional frente a sua realidade e sua prática, de maneira a uni-las com a teoria.

A consolidação de melhores desempenhos, tanto dos alunos quanto dos professores, é um caminho essencial a ser trilhado pelos envolvidos com o campo da educação formal.

A era da Tecnologia da Informação e Comunicação (TIC) tem possibilitado inúmeros campos de formação, seja ela inicial ou continuada. Cabe destacar que a produção docente é fortalecida através de saberes pedagógicos elaborados ao longo do processo de composição da vida acadêmica e profissional. Analisar e discutir a real importância dessa formação torna-se um instrumento de qualificação para o contexto educacional.

Alicerçado nesta perspectiva, nos deparamos com políticas públicas, implantadas e implementadas ao longo dos últimos anos, que vêm se expandindo a cada dia, se tornando, então, necessário ampliar os conhecimentos que abarcam este cenário. Nesta direção, aprofundar reflexões, bem como discussões sobre as possibilidades ofertadas, no que tange a formação inicial e continuada, é imprescindível.

RC: 105006

Disponível em: https://www.nucleodoconhecimento.com.br/educacao/enfrentamentos-dosdesafios 
Na conjuntura múltipla das políticas públicas educacionais, tem se observado planos, metas, propostas de debates, bem como projetos a serem aplicados na educação nacional. São longas as discussões que visam solucionar os desafios somados desde a implementação do ensino público no Brasil. Porém, vale pontuar que tais discussões ainda não alcançaram com sucesso o objetivo principal extensivo a todos, de forma a consolidar uma educação com qualidade.

Para que esse objetivo seja atingido, a educação deve ser vista pela sociedade contemporânea como prioridade e, com isso, garantida pelas políticas públicas nacionais.

Como consequência desta fragilidade, existem diversos empecilhos no que tange o acesso e a permanência dos educandos nos bancos escolares do Brasil. Para tanto, objetivando equacionar tais dificuldades, torna-se necessário refletir sobre as vertentes que conduzem o cenário educacional discutido neste trabalho. Assim sendo, é necessário sinalizar as várias barreiras que a educação formal enfrenta na busca de uma educação de qualidade. Dentre tais pontos motivadores, podemos elencar alguns que influenciam fortemente no cenário educacional, como: a) a falta de infraestrutura nas instituições escolares; b) a escassez dos recursos didáticos e paradidáticos nas unidades escolares; c) a subutilização das verbas destinadas à educação pública; d) as fragilidades na formação inicial e continuada dos professores; entre outras. Somada durante anos, toda essa carência na área da educação gerou grandes agravamentos, sobre os quais se há a obrigação de refletir, para que se busque por meios de auxiliar os que são prejudicados, seja de modo direto ou indireto, pelo descaso.

RC: 105006

Disponível em: https://www.nucleodoconhecimento.com.br/educacao/enfrentamentos-dosdesafios 
É importante salientar que a Constituição Federal de 1988, em seu artigo 205, destaca que:

\begin{abstract}
A educação, direito de todos e dever do Estado e da família, será promovida e incentivada com a colaboração da sociedade, visando ao pleno desenvolvimento da pessoa, seu preparo para o exercício da cidadania e sua qualificação para o trabalho (BRASIL, 1988).
\end{abstract}

Seguindo esse pensamento, o Estado vem propondo políticas públicas na busca de subsidiar e atender o que é garantido por lei em relação à educação, assim como também vem oferecendo e implementando, ao longo dos anos, vários projetos na área da educação.

Para Lopes e Amaral (2008, p. 5) as Políticas Públicas são:

\begin{abstract}
A totalidade de ações, metas e planos que os governos (nacionais, estaduais ou municipais) traçam para alcançar o bem-estar da sociedade e o interesse público. É certo que as ações que os dirigentes públicos (os governantes ou os tomadores de decisões) selecionam (suas prioridades) são aquelas que eles entendem serem as demandas ou expectativas da sociedade.
\end{abstract}

Convém salientar que o Ministério da Educação (MEC) vem implementando ações públicas com o intuito de atender as legislações vigentes no âmbito educacional. Em vista disso, na busca por qualidade para a educação brasileira, o Governo Federal oferece políticas públicas à sociedade contemporânea. Porém, é necessário discutir a efetivação de tais procedimentos.

Para tal, este estudo focou especificamente na formação inicial e continuada dos docentes como elemento significativo para a consistência de uma educação formal de excelência.

$\mathrm{Na}$ educação pública, ao analisar-se a prática pedagógica, pôde-se perceber que a formação dos docentes influencia diretamente na qualidade do ensino.

RC: 105006

Disponível em: https://www.nucleodoconhecimento.com.br/educacao/enfrentamentos-dosdesafios 
O docente, em sua formação inicial, deve ser conscientizado que não há seres "educados" e "não educados" e, também, que não existem seres detentores de toda sabedoria. Somos seres inacabados e estamos todos nos educando (FREIRE, 2013). Nesta perspectiva, o professor está sempre em processo de formação.

Vários são os pontos que estão sendo aprimorados na formação do docente. Dentre eles, podemos citar a relação que o professor precisa desenvolver com a questão da ética profissional, ou seja, a ética na docência é primordial. Além disso, mesmo com as dificuldades que enfrentam no seu cotidiano escolar, os educadores ainda precisam encarar o desafio de que não existe fórmula secreta e muito menos soluções prontas, mas sim: pesquisa, questionamentos, vocação e empenho na vida profissional.

Muitos docentes, em alguns casos, justificam sua má atividade na sala de aula por conta do cansaço, a impaciência e/ou desânimo com a profissão devido ao peso de uma baixa remuneração, desvalorização social, falta de ações públicas para apoiar o seu trabalho, entre outros fatores.

Nóvoa (1992, p. 24) aponta que:

[...] a formação de professores pode desempenhar um papel importante na configuração de uma "nova" profissionalidade docente, estimulando a emergência de uma cultura profissional no seio do professorado e de uma cultura organizacional no seio das escolas.

Portanto, refletir sobre a contribuição da formação inicial e/ou continuada contribui muito para a reconfiguração do cenário educacional no que tange a prática pedagógica do docente.

RC: 105006

Disponível em: https://www.nucleodoconhecimento.com.br/educacao/enfrentamentos-dosdesafios 


\section{FORMAÇÃO INICIAL: DIMENSÃO DA CONSTRUÇÃO DA IDENTIDADE PEDAGÓGICA DO DOCENTE}

A configuração da formação inicial do educador valoriza o processo de identidade dos profissionais que atuarão no campo educacional. Esta etapa é de extrema significância no cenário escolar, uma vez que é neste ambiente de aprendizagem que os futuros docentes recebem as primeiras orientações pedagógicas.

De acordo com Pimenta (2008, p. 18), "[...] espera-se que a licenciatura desenvolva nos alunos conhecimentos e habilidades, atitudes e valores que thes possibilitem permanentemente irem construindo seus saberes-fazeres docentes [...]". Assim sendo, esta formação possibilita que o futuro professor analise a proposta do seu fazer pedagógico, de maneira que ele tenha consciência da necessidade de unir as teorias apresentadas ao longo da formação à prática docente, que se dispõe a ser executada. Diante disso, transformar e contribuir com os fomentos que as práticas pedagógicas ofertadas no campo educacional podem proporcionar torna-se um caminho no qual o embasamento teórico e a criticidade podem gerar melhorias no desempenho do professor em sala de aula, assim como na obtenção de bons resultados por parte dos discentes.

Para Freire (2013, p. 34):

[...] a prática educativa tem de ser, em si, um testemunho rigoroso de decência e de pureza. Uma crítica permanente aos desvios fáceis com que somos tentados, às vezes ou quase sempre, a deixar as dificuldades que os caminhos verdadeiros podem nos colocar. Mulheres e homens, seres histórico-sociais, nos tornamos capazes de comparar, de valorar, de intervir, de escolher, de decidir, de romper, por tudo isso, nos tornamos seres éticos.

Atualmente, algumas destas formações iniciais se encontram distantes da prática pedagógica e da realidade vivida nesta profissão. Cabe ressaltar que a formação deve

RC: 105006

Disponível em: https://www.nucleodoconhecimento.com.br/educacao/enfrentamentos-dosdesafios 
contribuir para a reflexão a respeito do processo ensino-aprendizagem, por meio da qual se é possível buscar, de modo crítico, meios de superar, de forma ética, todos os desafios que rondam o cotidiano educacional (FREIRE, 2013).

Nóvoa (1992, p. 24) destaca que "[...] a formação de professores tem ignorado, sistematicamente, o desenvolvimento pessoal, confundindo "formar" e "formar-se", não compreendendo que a lógica da atividade educativa nem sempre coincide com as dinâmicas próprias da formação". Valorizando a importância de consolidar esta formação inicial em conjunto com o ambiente escolar, as experiências, as situaçõesproblemas e a prática pedagógica.

O objetivo principal da formação inicial é apresentar teorias, de modo a envolver o professor e, desta forma, instigá-lo a refletir a respeito das mudanças e das situações que ocorrem e podem ocorrer durante o período de atuação pedagógica. Como relata Perrenoud (1993, p. 138), "[...] a formação deixou de ser normalizada, já não pretende dar a resposta certa para cada situação tipo, mas sim dar recursos com vista a analisar e a enfrentar uma grande variedade de situações".

Os desafios a serem enfrentados na sala de aula pelos docentes recém-formados são variados. A preocupação de o que fazer e como fazer são sentimentos que têm origem na formação inicial. Vale destacar que estes questionamentos norteiam ou deveriam nortear o currículo disponibilizado para os cursos de formação inicial do docente.

A construção da prática pedagógica docente parte da premissa estruturada em uma tríade, que se inicia na formação inicial (na perspectiva dos saberes construídos inicialmente), perpassa, então, pela formação continuada (que vem a ser os saberes constituídos no processo cotidiano das salas de aulas, no âmbito da atuação da equipe pedagógica escolar e institucional) e pelas modalidades de ensino oferecidas em ambientes externos, por iniciativa e necessidade do professor. Essa tríade se fecha nos meios, nos recursos didáticos existentes que possibilitam a prática efetiva RC: 105006

Disponível em: https://www.nucleodoconhecimento.com.br/educacao/enfrentamentos-dosdesafios 
da construção de saberes pelos alunos, ou seja, nos recursos que viabilizam a aplicabilidade e a efetivação do processo de aprendizagem.

Nesse sentido, a formação inicial torna-se o começo de todo o processo de formação docente, no qual o educando passa a tomar conhecimento das habilidades e competências que precisam ser fomentadas e desenvolvidas, a fim de que a execução futura do ato pedagógico possa ser o melhor possível.

Cabe ressaltar que existem alguns fatores que, por vezes, ocasionam impactos no aprimoramento dos processos de formação inicial docente. Para Mello (2000, p. 2):

A democratização do acesso e a melhoria da qualidade da educação básica vêm acontecendo num contexto marcado pela modernização econômica, pelo fortalecimento dos direitos da cidadania e pela disseminação das tecnologias da informação, que impactam as expectativas educacionais ao ampliar o reconhecimento da importância da educação na sociedade do conhecimento.

Para além da formação inicial, nos deparamos com a democratização do acesso e o aprimoramento da educação básica que vem se desenhando num cenário marcado pela redemocratização do Brasil e por significativas alterações nas expectativas e demandas educacionais da sociedade brasileira. Vale destacar que o avanço das tecnologias da informação e das comunicações está impactando as formas de relações sociais, de organização do trabalho e do exercício da cidadania (BRASIL, 2000).

Um dos contrapontos que precisam ser levantados em relação a formação inicial e a atualidade das situações vivenciadas nas escolas públicas brasileiras no campo pedagógico, passam pela afirmação apontada na Proposta de Diretrizes para Formação Inicial de Professores da Educação Básica, em Cursos de Nível Superior, em que se é destacado que:

RC: 105006

Disponível em: https://www.nucleodoconhecimento.com.br/educacao/enfrentamentos-dosdesafios 
A formação inicial de professores fica, geralmente, restrita à sua preparação para a regência de classe, não tratando das demais dimensões da atuação profissional como sua participação no projeto educativo da escola, seu relacionamento com alunos e com a comunidade. Dificilmente são levadas em conta outras dimensões do exercício profissional, ficando ausentes, também, as discussões sobre as temáticas relacionadas mais propriamente ao sistema educacional e à atuação da categoria profissional. Esse problema é agravado pelas frágeis relações interinstitucionais entre escola de formação, associações profissionais, sindicatos, que possibilitem tais vivências e as ampliem para além da instituição de formação (MINISTÉRIO DA EDUCAÇÃO, 2000, p. 27).

Deste modo, podemos refletir que a formação inicial dos docentes precisa ser aperfeiçoada de tal forma que abrace todas as questões sociais e educacionais que estimulam e contribuem para o cenário escolar na atualidade.

Considerar a complexidade dos processos que estão envolvidos na educação brasileira como fator que possibilita a formação inicial, necessária e substancial para uma futura prática docente equilibrada e de construção efetiva na qualidade da educação, é primordial.

O debate travado, no que se refere às instituições responsáveis pela formação inicial, muitas vezes passa pela reflexão da valorização dos saberes docentes a partir da instigação da formação do professor por meio do movimento de construção de educadores pesquisadores. Segundo André (2012, p. 57), "essas concepções têm sido amplamente divulgadas no Brasil, ao fazer parte dos conteúdos e da bibliografia dos cursos de formação inicial e continuada do professor [...]".

É justamente através da pesquisa que reflexões são solidificadas, bem como equacionadas. A investigação possibilita a análise que, de fato, altera práticas pedagógicas e justifica, de forma fundamental, tais alterações.

Do ponto de vista da questão de formação de professores e da emancipação pedagógica no seio da educação formal, em que se pesa as muitas diferenças e as

RC: 105006

Disponível em: https://www.nucleodoconhecimento.com.br/educacao/enfrentamentos-dosdesafios 
variações presentes na incorporação das premissas e necessidades apontadas, em prol da qualidade da prática docente, muito é falado e compartilhado pelos pesquisadores que compõem o grupo de formadores.

Mello (2000, p. 8) salienta que:

A mudança nos cursos de formação inicial de professores terá que corresponder, em extensão e profundidade, aos princípios que orientam a reforma da educação básica, mantendo com esta uma sintonia fina. Não se trata de criar modismos, mas de buscar modalidades de organização pedagógica e espaços institucionais que favoreçam a constituição, nos futuros professores, das competências docentes que serão requeridas para ensinar e fazer com que os alunos aprendam de acordo com os objetivos e diretrizes pedagógicas traçados para a educação básica.

Dessa maneira, o que deve existir é a consciência construída de forma a valorizar comprometimento com o ensino e com a formação do docente, que irá fomentar práticas pedagógicas no contexto escolar da educação formal. Pensar nas fragilidades que a formação do professor tem enfrentado é um canal de possibilidades para ofertas e demandas que se propõem a discutir e a aprofundar caminhos substanciais da formação do profissional da educação.

\section{FORMAÇÃO CONTINUADA: CENÁRIOS DE NOVAS CONJUNTURAS}

Esta parte do estudo propõe apresentar algumas reflexões sobre a importância da formação continuada do docente que atua na escola pública. Tais reflexões têm como base a análise dos fragmentos das leituras realizadas a respeito da temática proposta. Vale destacar que os autores estudados são renomados e muito utilizados em pesquisas sobre o tema.

Para que o docente possa obter e exercer a sua habilitação, sua formação profissional vai muito além da formação inicial. Este processo de formação do professor se dá de RC: 105006

Disponível em: https://www.nucleodoconhecimento.com.br/educacao/enfrentamentos-dos$\underline{\text { desafios }}$ 
forma contínua e deve ser constituída permanentemente através de ações individuais, institucionais e orientadas. Essas condições são possíveis para o docente devido a adoção da postura pesquisadora e reflexiva, de modo que, através do seu cotidiano escolar, possa perceber a necessidade de inovação e de busca por novos saberes, que irá enaltecer sua função de educador e, assim, permitirá que ele utilize esses saberes, esse novo significado, em prol da aprendizagem dos seus alunos.

Portanto, é importante destacar que as descrições a respeito da necessidade efetiva de cursos que possibilitem a formação continuada de qualidade, são emergentes. Para Chimentão (2009, p. 03):

o processo de formação continuada de professores não é novidade. Vários são os autores que apresentam discussões sobre esta temática, e ressaltam sua relevância para os profissionais do ensino, como Candau (1997), Nascimento (2000), Pimenta (2002), entre outros. No entanto, salientamos sua importância, relacionando-a com a necessidade de mudança da escola

A sociedade contemporânea tem apresentado mudanças em todos os setores e segmentos, inclusive na escola. Essas mudanças têm gerado novas perspectivas no pensar da função da instituição, bem como do papel do educador frente a este contexto. Diante disso, a escola tem vivenciado múltiplas facetas, a fim de equacionar as exigências educacionais. Uma dessas facetas diz respeito à formação continuada dos professores.

A formação continuada é um processo permanente e necessário para a atividade profissional, realizado após a formação Inicial, com o objetivo de assegurar um ensino de melhor qualidade aos alunos. Sendo assim, ela passa a ser um dos pré-requisitos para a transformação do professor, pois é através do estudo, da pesquisa, da reflexão, do constante contato com novas concepções, que a mudança se torna possível.

RC: 105006

Disponível em: https://www.nucleodoconhecimento.com.br/educacao/enfrentamentos-dosdesafios 
Essas indicações alinham-se com a formação continuada como um processo que tem como objetivo promover mudanças no pensar, na cognição do professor, ou seja, indicando a necessidade de processos de reflexão sobre os conteúdos, de modo a fortalecer o domínio de saberes capazes de indicar novas formas de atuação mediante o perfil apresentado pelos alunos. Para tal, a formação continuada tende a estruturar novas formas do pensar pedagógico, em que os processos de busca por essas novas formas necessitam ser incorporados e não apenas ocorrer a partir de processos meramente cognitivos, ou seja, deve-se abranger os processos socioafetivos e culturais (GATTI, 2003).

Para Gatti (2003, p. 193):

É preciso ver os professores não como seres abstratos, ou essencialmente intelectuais, mas, como seres essencialmente sociais, com suas identidades pessoais e profissionais, imersos numa vida grupal na qual partilham uma cultura, derivando seus conhecimentos, valores e atitudes dessas relações, com base nas representações constituídas nesse processo que é, ao mesmo tempo, social e intersubjetivo. Há também que se considerar o papel de eventos mais amplos, sejam sociais, políticos, econômicos ou culturais, com seus determinantes que perpassam a vida grupal ou comunitária. Sabemos que a interação desses fatores molda as concepções sobre educação, ensino, papel profissional, e as práticas a elas ligadas, concepções e práticas estas que, por sua vez, são estruturalmente delimitadas pela maneira que as pessoas se veem, como estruturam suas representações, como se descrevem, como veem os outros e a sociedade à qual pertencem.

Seguindo a perspectiva de Gatti (2003), o professor é um ser social com identidade pessoal e profissional, que partilha de culturas, valores e atitudes vindas de sua formação de vida e formação inicial. Esses processos e saberes que constituem inicialmente o professor, impactam diretamente no processo de formação continuada, no qual a realidade atual (necessidades) sinaliza novos caminhos pedagógicos, gerando a busca por novas formas de atuação. Nesse momento, através de uma influência grupal (interação social com demais pares), constitui-se a essência e

RC: 105006

Disponível em: https://www.nucleodoconhecimento.com.br/educacao/enfrentamentos-dosdesafios 
objetivo maior da formação continuada: a busca, a pesquisa e o aperfeiçoamento pedagógico.

Percebendo essa necessidade, a formação continuada vai sendo gerada, buscando trazer respostas às questões desafiadoras das salas de aula, indicando caminhos a seguir que irão favorecer a prática pedagógica. Sendo assim, ela incute significado/sentido ao trabalho pedagógico, através da relação estabelecida entre as bases teóricas, que indicam os caminhos e a prática pedagógica que comprovam ou não a efetivação desse conjunto através dos resultados obtidos. A realidade em que o docente está inserido, seus anseios, dúvidas e sugestões, também devem ser levados em consideração, para que, em conjunto, possa ser repensado esses desafios e essas necessidades, de modo a ressignificar e reelaborar suas práticas cotidianas.

Para Chimentão (2009, p. 02), "[...] estamos vivenciando um momento em que a informação e o conhecimento são requisitos indispensáveis para a vida profissional". Como todos os processos exitosos, é preciso que haja significado para os envolvidos, pois isso motiva a busca, promove o interesse e a vontade de alcançar o sucesso. $\mathrm{Na}$ formação continuada, não ocorre de forma diferente. É preciso que a formação ocorra de modo a incutir sentido ao trabalho pedagógico, apresentando significado para o professor e sendo eficaz no processo de aprendizagem e de desenvolvimento profissional. Esse link entre significado e eficiência da formação continuada parte da premissa da relação articulada entre a teoria e a prática. É preciso saber os conceitos e como aplicá-los na prática, obtendo bons resultados ou, na medida do possível, até mesmo avanços, até se alcançar a plenitude dos objetivos.

Sendo assim, para provocar estas reflexões que conduzem a probabilidade de mudança, é preciso que haja um movimento e transformação na postura e no fazer pedagógico do professor. Estes processos de alteração ocorrem com os professores

RC: 105006

Disponível em: https://www.nucleodoconhecimento.com.br/educacao/enfrentamentos-dosdesafios 
se eles forem preparados com uma forte fundamentação teórica, de modo a desenvolver a capacidade de análise crítica acerca de todos os aspectos que compõem e influenciam o contexto escolar, uma vez que a informação e o conhecimento são requisitos indispensáveis à vida profissional de qualquer indivíduo, sendo mais indispensáveis ainda para o professor (CHIMENTÃO, 2009).

A atuação docente de qualidade é autovalorizada através da atuação com outros indivíduos, pela troca de experiência e pelo compartilhamento de dúvidas. Deste modo, a individualidade limita a possibilidade de expansão de conhecimentos, uma vez que, por meio da relação com seus pares, apresenta-se a possibilidade de o professor desmistificar situações, abrindo possibilidades de atuação didático pedagógica que venham a sanar suas limitações e dificuldades, proporcionando novas experiências, novas pesquisas e novas formas de ver e pensar a escola e seus alunos.

A sociedade do conhecimento está em constante mudanças e impulsiona as pessoas a sempre saberem mais, pois o que se sabe hoje, "amanhã" já é superado por outras informações e a cada dia surgem mais desafios, tanto no campo pessoal quanto no profissional. No cenário educacional atual, não é diferente, pois os alunos de hoje apresentam "sede" de saber, porém, ao mesmo tempo, também apresentam inquietude, uma vez que já não apresentam o mesmo poder de concentração. Os valores sociais se transformaram e, por isso, é necessário que se repense as práticas pedagógicas utilizadas há tempos pelos professores, assim como a própria imagem do professor.

A busca constante por novos saberes concretiza-se através da combinação das formações iniciais e na troca (grupos), porém, ela só será alcançada se for ressignificada pelo professor. Diante disso, o processo de formação continuada também acontece de forma individualizada, ou seja, o docente, consciente de sua

RC: 105006

Disponível em: https://www.nucleodoconhecimento.com.br/educacao/enfrentamentos-dosdesafios 
necessidade de aprendizagem, apresenta iniciativa própria de qualificar o seu trabalho pedagógico.

Nesta perspectiva, a formação continuada, de acordo com as suas especificidades, apresenta-se como ferramenta essencial para iniciação deste processo de adequação às mudanças, partindo da percepção de necessidade da busca, vinda do professor.

Segundo Wengzynski e Tozetto (2012, p. 3):
A formação continuada assim entendida como perspectiva de mudança das práticas no âmbito dos docentes e da escola possibilita a experimentação do novo, do diferente a partir das experiências profissionais que ocorrem neste espaço e tempo orientando um processo constante de mudança e intervenção na realidade em que se insere e predomina esta formação.

As instituições de ensino estão sempre em busca de realizar melhorias na qualidade do ensino que oferta, o que faz com que elas invistam em formação para a sua equipe de docentes, de modo a proporcionar serviços de maior qualidade.

Cabe salientar que a legislação educacional brasileira vigente estabelece diretrizes para que este processo de formação seja atingido. A Lei de Diretrizes e Bases da Educação Nacional, no 9394, de 20 de dezembro de 1996, em seu artigo 67 estabelece que:

Art. 67. Os sistemas de ensino promoverão a valorização dos profissionais da educação, assegurando-Ihes, inclusive nos termos dos estatutos e dos planos de carreira do magistério público:

I- Ingresso exclusivamente por concurso público de provas e títulos;

II- Aperfeiçoamento profissional continuado, inclusive com licenciamento periódico remunerado para esse fim;

III- Piso salarial profissional;

RC: 105006

Disponível em: https://www.nucleodoconhecimento.com.br/educacao/enfrentamentos-dosdesafios 
IV- Progressão funcional baseada na titulação ou habilitação, e na avaliação do desempenho;

V- Período reservado a estudos, planejamento e avaliação, incluído na carga de trabalho; VI - condições adequadas de trabalho (BRASIL,1996).

Já a Lei n 11.738, de 16 de julho de 2008, que Regulamenta a alínea "e" do inciso III do caput do art. 60 do Ato das Disposições Constitucionais Transitórias, para instituir o piso salarial profissional nacional para os profissionais do magistério público da educação básica, estabelece em seu artigo $2^{\mathrm{a}}$, parágrafo $4^{\circ}$ que "na composição da jornada de trabalho, observar-se-á o limite máximo de 2/3 (dois terços) da carga horária para o desempenho das atividades de interação com os educandos." (BRASIL, 2008).

Analisando as legislações apontadas, podemos perceber que existe amparo das legislações vigentes que garante a formação continuada aos professores em pleno exercício de suas funções.

O Ministério da Educação (MEC) disponibiliza cursos de atualização gratuitos para os docentes, visando aprimorar a sua formação continuada. Vale destacar que as ofertas atingem vários setores da educação, uma vez que todos os níveis precisam de capacitações em prol da qualidade.

Todo este cenário discutido considera a dimensão material das condições de oferta, que implica na observação das dificuldades apresentadas pelos docentes. Os espaços integram a dimensão pedagógica das escolas públicas brasileiras e, claro, a necessidade de adequação das possibilidades de formação.

O canal, muitas vezes utilizado para a percepção das necessidades, é o Índice de Desenvolvimento da Educação Básica (ldeb) ${ }^{[3]}$. É a partir desse repositório que o MEC disponibiliza as capacitações.

RC: 105006

Disponível em: https://www.nucleodoconhecimento.com.br/educacao/enfrentamentos-dosdesafios 
Portanto, percebemos o quão importante a formação continuada dos professores é para a educação nacional

\section{IMPACTOS DA FORMAÇÃO INICIAL E CONTINUADA NA PRÁTICA DOCENTE E NOS PROCESSOS DE APRENDIZAGEM}

De acordo com as transformações sociais da contemporaneidade, as instituições de ensino vêm adquirindo responsabilidades cada vez mais complexas. Diante destas condições, o docente deve estar preparado para lidar com esse cotidiano escolar desafiador. Para tal, a formação muito contribui para a efetivação de práticas pedagógicas que, de fato, façam a diferença e adicionem saberes no fazer pedagógico em prol da qualidade da educação formal.

Neste aspecto, é preciso refletir sobre como se dá o processo de formação inicial e continuada, de modo a contemplar, na realidade atual, o 'chão' da escola em toda a estrutura curricular e na formação continuada, mantendo essa base e qualificando-a constantemente no cotidiano.

Quando a formação inicial deixa lacunas, a formação continuada, que ocorre em tempo real, atende à demanda de aperfeiçoamento, proporcionando a possibilidade de amenizar os efeitos negativos deste início 'incompleto', qualificando melhor a prática pedagógica.

Mesmo que o docente tenha sua formação inicial e continuada, pode haver grande probabilidade desses profissionais não executarem uma prática pedagógica de qualidade, com criticidade. Nesse caso, percebe-se uma deficiência na formação desses profissionais.

Diante do exposto, Mello (2000, p. 14) salienta que "a importância da prática decorre do significado que se atribui à competência do professor para ensinar e fazer

RC: 105006

Disponível em: https://www.nucleodoconhecimento.com.br/educacao/enfrentamentos-dosdesafios 
aprender. Competências são formadas na prática, portanto isso deve ocorrer necessariamente em situações concretas, contextualizadas". Ao associar a essa ideia, fatores como, motivação, interesse, contexto social e velocidade da informação, transforma-se, por meio da adoção de algumas posturas, a formação obtida por esses profissionais.

O quadro apresentado em seguida resume as reflexões discutidas anteriormente, de modo a fomentar a importância da formação inicial e continuada do docente como um dos alicerces para a educação formal na perspectiva da qualidade educacional.

Figura 1 - Importância da formação inicial e continuada do docente

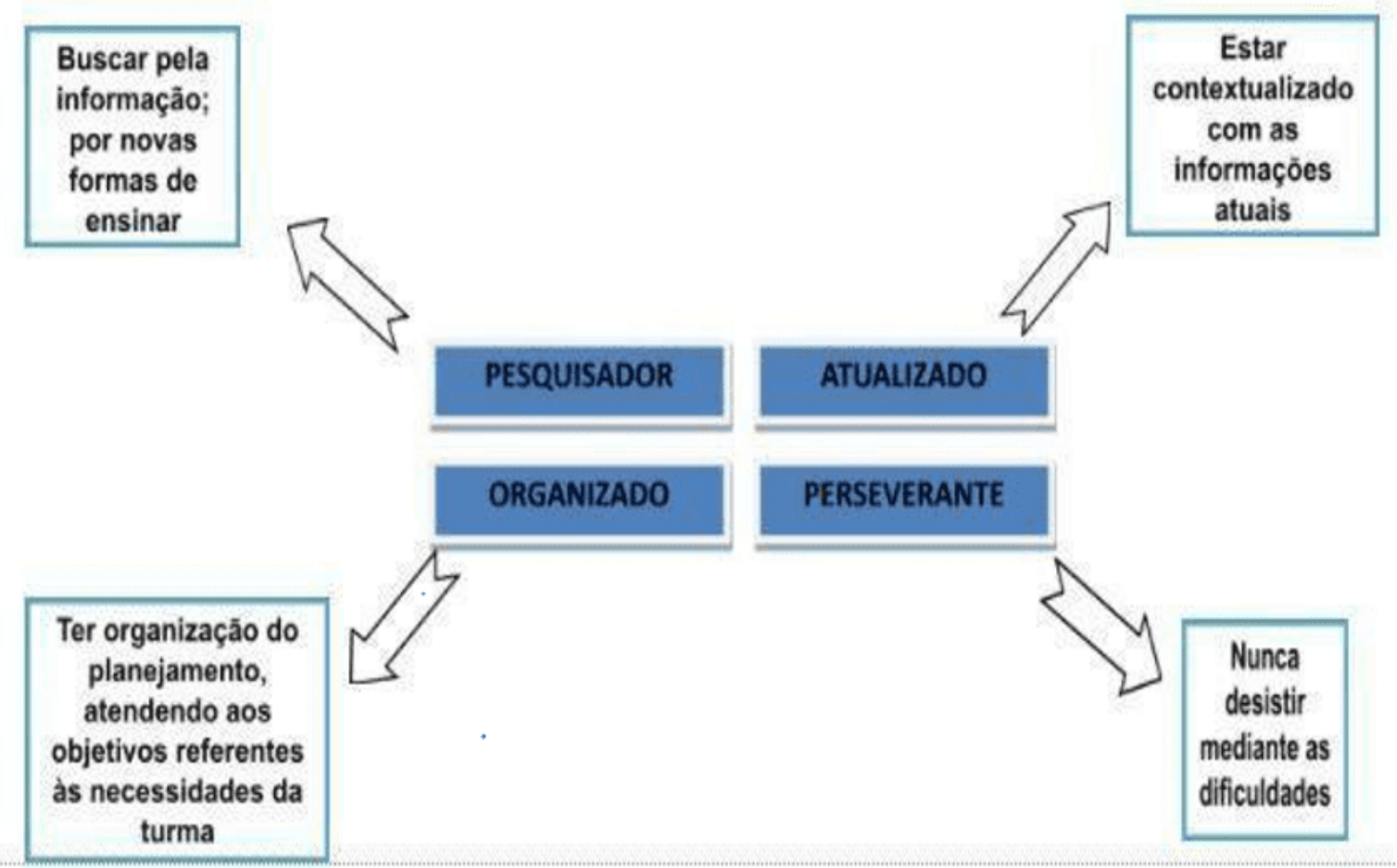

Fonte: Elaborado pelos Autores.

Vale destacar que, sem essa junção de compromissos que geram ações, as formações não efetivam a sua principal missão, que é instrumentalizar este

RC: 105006

Disponível em: https://www.nucleodoconhecimento.com.br/educacao/enfrentamentos-dosdesafios 
profissional para atuar pedagogicamente, de forma a garantir o direito de aprendizagem dos alunos.

Quando podemos, através da prática realizada em sala de aula, perceber o distanciamento que existe de um docente para o outro, mesmo dentro da mesma rede de ensino e compartilhando das mesmas formações continuadas, claramente entende-se o porquê alguns são considerados 'bons professores' e outros não. Esses ditos 'bons professores' conseguem concretizar sua prática pedagógica indo além do que teve contato em suas formações.

Segundo Cunha (2012, p. 29):

Unir ensino e pesquisa significa caminhar para que a educação seja integrada, envolvendo estudantes e professores numa criação do conhecimento comumente partilhado. A pesquisa deve ser usada para colocar o sujeito dos fatos, para que a realidade seja apreendida e não somente reproduzida.

$\mathrm{Na}$ área educacional, o educador vive em constante transformação e, unido a essas mudanças, também há o sistema burocrático escolar, no qual os docentes, por vezes, são cobrados a seguir normas e exigências administrativas, que, consequentemente, "secam" seus ideais e sua autonomia. Por esse motivo, muitos professores sentemse desestimulados, desanimados e tornam-se profissionais "robotizados" pelo sistema. Em contrapartida, outros professores veem, em meio ao caos, um jeito, uma força, um apoio e a persistência de buscar, lutar, repensar e melhorar o seu desempenho e o de seus alunos.

Para Freire (2005, p. 77), “a educação que se impõe aos que verdadeiramente se comprometem com a libertação não pode fundar-se numa compreensão dos homens como seres vazios, a quem o mundo encha de conteúdos".

RC: 105006

Disponível em: https://www.nucleodoconhecimento.com.br/educacao/enfrentamentos-dosdesafios 
Portanto, nas relações com o mundo e com a sociedade, o professor tem uma tarefa contributiva na perspectiva educacional, ou seja, por meio dos conteúdos apresentados na sala de aula, ele precisa proporcionar experiências aos seus alunos, e, para tal, sua prática pedagógica necessita estar sempre em processo de evolução, pois é através da formação que tal ação se torna possível. Podemos citar a experiência vivida pelos docentes como sendo mais um fator que pode influenciar sua prática em sala de aula.

Cunha (2012, p. 32) discute que:

o mesmo fato pode ter significados diferentes para pessoas diferentes. O fato de o professor ter tido uma educação autoritária e punitiva pode fazê-lo tentar repelir esta forma no seu cotidiano docente, mas pode também, levá-lo a repetir esta prática.

Todas as circunstâncias vividas por esse profissional, as suas concepções e suas participações em meios religiosos, sociais, entre outros, podem interferir de forma positiva ou não no seu modo de agir, uma vez que eles se apropriam daquilo que thes é mais pertinente e que vai de acordo com seus saberes histórico-sociais.

Através da pesquisa realizada por Cunha (2012) em instituições escolares, buscando "bons professores" e suas práticas, ouviu-se dos alunos quais são as características principais desses profissionais. A autora pontua as expressões que articulam a ideia de bons professores, e "... entre as expressões usadas estão "é amigo", "compreensivo", "é gente como a gente", "se preocupa conosco", "é disponível mesmo fora da sala de aula", "coloca-se na disposição do aluno", "é honesto nas observações", "é justo", etc" (CUNHA, 2012, p. 61).

Com essa percepção de como os alunos consideram bons professores, entende-se que o afeto está intrinsecamente ligado ao profissional docente, o que ressalta a não neutralidade no ato pedagógico, algo que também ultrapassa as barreiras da formação inicial e continuada.

RC: 105006

Disponível em: https://www.nucleodoconhecimento.com.br/educacao/enfrentamentos-dosdesafios 
O embasamento teórico adquirido pelo docente se apresenta no modo em que ele reflete, repensa a teoria e a aplica, com criticidade e comprometimento, em uma educação de qualidade, que visa formar cidadãos críticos e reflexivos diante de seus direitos e deveres na sociedade. Cunha (2012, p. 63) afirma que "para os alunos atuais, o bom professor é aquele que domina o conteúdo, escolhe formas adequadas de apresentar a matéria e tem bom relacionamento com o grupo".

Desse modo, o docente deve ver significado e fundamento no que ensina, para que possa instigar seus alunos a se interessarem cada vez mais pelos conteúdos, fazendo com que eles enxerguem a necessidade desses assuntos em sua realidade e em sua vida.

Cunha (2012, p.99) sinaliza que:

A produção do conhecimento é entendida aqui como a atividade do professor que leva à ação, à reflexão, à curiosidade, ao questionamento exigente, à inquietação e à incerteza. É o oposto da transmissão do conhecimento pronto, acabado. É a perspectiva de que ele possa ser criado e recriado pelos estudantes e pelos professores na sala de aula.

Ser um docente comprometido dentro da sala de aula, apesar de todas as dificuldades encontradas no campo educacional, torna-se possível e sem maiores sacrifícios se essa profissão é vista como algo que Ihes dá prazer. Para Cunha (2012, p. 113), “"o gostar de ensinar" foi o aspecto mais apontado junto com o "gostar de gente". Os professores revelam que não sabem se isto se ensina ou faz parte das tendências ou vocação das pessoas. O fato é que consideram estes pontos fundamentais".

Os desafios que se mostram durante a formação e prática do docente são muitos, porém, se a teoria estiver em conjunto com a reflexão do contexto histórico-social em que o docente vive e atua, de modo a contribuir para a análise de suas experiências, de seus atos pedagógicos e de sua condição, é possível aumentar cada vez mais o

RC: 105006

Disponível em: https://www.nucleodoconhecimento.com.br/educacao/enfrentamentos-dosdesafios 
grupo de "bons professores"' com boas práticas, que apresentam desempenhos e resultados melhores tanto em relação aos docentes quantos aos alunos.

\section{CONSIDERAÇÕES FINAIS}

Diante das diferentes culturas, dos desafios que percorrem o cotidiano educacional e das exigências de uma sociedade em constante transformação, considerou-se, com esse estudo, que a formação inicial e são de grande importância para o desempenho dos docentes em relação a todas as dificuldades enfrentadas no dia-a-dia, uma vez que elas auxiliam os profissionais na obtenção de melhores resultados com os discentes, assim como no desenvolvimento de um ambiente crítico e ético. Porém, o embasamento teórico, aplicado de forma evasiva, sem reflexão, não terá resultados positivos. Essas formações devem ser aceitas, compreendidas e repensadas pelos docentes de forma sistemática. Suas experiências, convívio social e percepção de mundo também fazem parte deste processo de crescimento do ato pedagógico.

$\mathrm{Na}$ formação inicial e continuada, o profissional deve ser incentivado a pensar e repensar suas práticas frente a todas as transformações, eliminando um modelo de formação que tenha foco somente na teoria e que não respeite as práticas, as experiências e a realidade na qual os docentes estão inseridos.

Para Freire (2013), o momento de reflexão crítica sobre a prática é fundamental para formação permanente dos professores. É por meio do pensamento crítico a respeito da prática de hoje ou de ontem que se pode melhorar a próxima prática.

Por meio da análise da história da formação docente no Brasil, é possível observar algumas modificações e melhorias nas ações e nos planos elaborados, a fim de auxiliar os docentes na construção de seus conhecimentos e de apresentar compromisso com a qualidade e com a ética diante da prática em sala de aula. Sua

RC: 105006

Disponível em: https://www.nucleodoconhecimento.com.br/educacao/enfrentamentos-dosdesafios 
formação será continuamente construída através de sua prática quando ela for repensada e apoiada em um embasamento teórico adquirido durante sua formação.

Neste contexto, no qual as formações iniciais e continuadas são consideradas um dos alicerces para o sucesso educacional, o querer, o pensar, o refletir e avaliar, por parte dos docentes, tornam-se elementos fundamentais para que todo o conhecimento adquirido seja, de fato, transformado, de modo a gerar melhorias na prática do docente e no desempenho dos alunos.

\section{REFERÊNCIAS}

ANDRÉ, M. Pesquisa, formação e prática docente. In: ANDRÉ, M. (Org.). O papel da pesquisa na formação e na prática dos professores $12^{\mathrm{a}}$ ed. Campinas: Papirus, 2012.

BRASIL. Lei de Diretrizes e Bases da Educação Nacional n.ำ 9.394, de 20 de dezembro de 1996. Estabelece as diretrizes e bases da educação nacional.

Brasília, DF, dez. $1996 . \quad$ Disponível em: http://www.planalto.gov.br/ccivil_03/leis/L9394.htm. Acesso em: 18 jun. 2016.

BRASIL. Lei no 11.738, de 16 de julho de 2016. Regulamenta a alínea "e" do inciso III do caput do art. 60 do Ato das Disposições Constitucionais Transitórias, para instituir o piso salarial profissional nacional para os profissionais do magistério público da educação básica. Brasília, DF, jul. 2016. Disponível em: http://www.planalto.gov.br/ccivil_03/_ato2007-2010/2008/lei/111738.htm. Acesso em: 18 jun. 2016.

MINISTÉRIO DA EDUCAÇÃO. Proposta de diretrizes para a formação de professores da Educação Básica, em cursos de nível superior. Maio de 2000. 
Disponível em: http://portal.mec.gov.br/cne/arquivos/pdf/basica.pdf. Acesso em: 18 jun. 2016.

CHIMENTÃO, L.K. O significado da formação continuada docente. In: Congresso Norte Paranaense de Educação Física Escolar, 2009. Disponível em: http://www.uel.br/eventos/conpef/conpef4/trabalhos/comunicacaooralartigo/artigoco moral2.pdf. Acesso em: 18 jun. 2016.

CUNHA, M. I. de. O bom professor e sua prática. 24르 ed. Campinas: Papirus, 2012. FREIRE, P. Pedagogia da autonomia: saberes necessários à prática educativa. 46ª ed. São Paulo: Paz e Terra, 2013.

FREIRE, P. Pedagogia do oprimido. 48ª reimpressão. Rio de Janeiro: Paz e Terra. 2005.

GATTI, B.A. Formação continuada de professores: a questão psicossocial. Cadernos de Pesquisa, n. 119, p. 191-204, julho de 2003. Disponível em: http://www.scielo.br/pdf/cp/n119/n119a10.pdf. Acesso em junho de 2016.

LOPES, B.; AMARAL, J. N. Políticas Públicas: conceitos e práticas. Belo Horizonte, MG: $2008 . \quad$ Sebrae, Disponível em: http://www.agenda21 comperj.com.br/sites/localhost/files/MANUAL\%20DE\%20POLIT ICAS\%20P\%C3\%9ABLICAS.pdf. Acesso em: 18 jun. 2016.

MELLO, G.N. Formação Inicial de professores para a Educação Básica: uma (re) visão radical. Revista São Paulo em perspectiva, v. 14, p. 98-110, 2000. Disponível em: http://www.scielo.br/pdf/spp/v14n1/9807.pdf. Acesso em: 18 jun. 2016.

RC: 105006

Disponível em: https://www.nucleodoconhecimento.com.br/educacao/enfrentamentos-dosdesafios 
NÓVOA, A. Formação de professores e profissão docente. $2^{\mathrm{a}}$ ed. Lisboa: D. Quixote, 1992.

PERRENOUD, P. Práticas Pedagógicas, Profissão Docente e Formação: perspectivas sociológicas. Lisboa: Publicações Dom Quixote, Instituto de Inovação Educacional, 1993.

PIMENTA, S. G. (Org.). Saberes pedagógicos e atividade docente. 6ª ed. São Paulo: Cortez, 2008.

WENGZYNSKI, D. C.; TOZETTO, S. S. A formação continuada face às suas contribuições para a docência. Disponível em: http://www.ucs.br/etc/conferencias/index.php/anpedsul/9anpedsul/paper/viewFile/210 7/513. Acesso em: 18 jun. 2016.

\section{APÊNDICE - REFERÊNCIA NOTA DE RODAPÉ}

3. O Índice de Desenvolvimento da Educação Básica (Ideb) foi criado pelo Inep em 2007 e representa a iniciativa pioneira de reunir em um só indicador dois conceitos igualmente importantes para a qualidade da educação: fluxo escolar e médias de desempenho nas avaliações. Ele agrega ao enfoque pedagógico dos resultados das avaliações em larga escala do Inep a possibilidade de resultados sintéticos, facilmente assimiláveis, e que permitem traçar metas de qualidade educacional para os sistemas. O indicador é calculado a partir dos dados sobre aprovação escolar, obtidos no Censo Escolar, e das médias de desempenho nas avaliações do Inep, o Saeb, para as unidades da federação e para o país, e a Prova Brasil, para os municípios. Disponível em < http://portal.inep.gov.br/web/portal-ideb/o-que-e-o-ideb> Acesso em junho de 2016.

Enviado: Junho, 2021.

RC: 105006

Disponível em: https://www.nucleodoconhecimento.com.br/educacao/enfrentamentos-dos$\underline{\text { desafios }}$ 
Aprovado: Janeiro, 2022.

RC: 105006

Disponível em: https://www.nucleodoconhecimento.com.br/educacao/enfrentamentos-dos$\underline{\text { desafios }}$ 